\title{
Note
}

\section{Application of Inorganic Membrane to Separation of Benzene and Cyclohexane with Supported Liquid Membranes Using Ionic Liquids}

\author{
*Michiaki Matsumoto, Hirotsugu Yabushita, Masakazu Mikami, and Kazuo Kondo \\ Department of Chemical Engineering and Materials Science, Faculty of Engineering, Doshisha University, \\ Tatara, Kyotanabe, Kyoto 610-0321, Japan
}

(Manuscript submitted March 25, 2007; accepted May 9, 2007)

\begin{abstract}
Application of inorganic membrane (Shirasu porous glass, SPG) to separation of benzene and cyclohexane with supported liquid membranes using ionic liquids, based on 1-alkyl-3-methylimidazolium was examined. Ionic liquids were stably kept in pores of a SPG support and benzene selectivity permeated the membranes as well as a polymeric membrane. Apparent diffusivities in the membrane using SPG were almost the same as those with the polymeric membrane.
\end{abstract}

Key words: liquid membrane, ionic liquid, inorganic membrane, benzene, cyclohexane, SPG

\section{Introduction}

In our previous papers, application of supported liquid membranes (SLMs) based on ionic liquids to separation of organic compounds and antibiotics were examined and we found that SLMs based on ionic liquids gave extremely stable membranes [1-4]. In these studies and most studies concerning SLMs, the membrane supports are polymeric [5]. However polymeric SLMs are more sensitive to temperature, $\mathrm{pH}$, chemical environment and physical stress [6,7]. Although ceramic supported membranes have potential to overcome the above difficulties, there are a few studies of ceramic supported membrane based on conventional organic solvents $[6,7]$ and no studies of those based on ionic liquids. In this study, we examine whether inorganic membrane can be utilized the SLMs based on ionic liquids. We raise the separation of benzene and cyclohexane as a model system which was previously reported using a polymeric SLM based on ionic liquids [1]. Shirasu porous glass (SPG) membranes, which have found many applications [8], were used as a ceramic support.

\section{Experimental}

Imidazolium-based ionic liquids, the hexafluorophosphates of 1-n-butyl- or 1-n-hexyl imidazolium, $\left[\mathrm{C}_{4} \mathrm{mim}\right]\left[\mathrm{PF}_{6}\right]$ and $\left[\mathrm{C}_{6} \mathrm{mim}\right]\left[\mathrm{PF}_{6}\right]$ were prepared as described in the previous paper[2]. The membrane materials were a hydrophilic polyvinylidene fluoride (PVDF, Millipore) with a pore size of $0.45 \mu \mathrm{m}$ and Shirasu porous glass (SPG, SPG techno) with a pore size of $0.4 \mu \mathrm{m}$. The thickness of PVDF and SPG membranes were $150 \mu \mathrm{m}$ and $766 \mu \mathrm{m}$, respectively. PVDF or SPG was impregnated with ionic liquid as described in the previous papers [1-3]. A membrane with an effective area, $A$, of $25 \mathrm{~cm}^{2}$ (PVDF) or $2.25 \mathrm{~cm}^{2}$ (SPG) was fixed in the apparatus. 50 $\mathrm{ml}$ of benzene and $50 \mathrm{ml}$ of cyclohexane were added into the feed phase and $100 \mathrm{ml}$ of hexadecane was poured into the receiving phase at $30^{\circ} \mathrm{C}$. The stirring speed of the magnetic bar in each cell was controlled at $300 \mathrm{rpm}$. 
Samples in receiving phase were withdrawn at regular time intervals. Then the concentrations of benzene and cyclohexane in receiving phase were measured by gas chromatography.

\section{Results and Discussion}

Figure 1 shows time courses of the concentrations of benzene and cyclohexane in the receiving phase under the condition where $\left[\mathrm{C}_{6} \mathrm{mim}\right]$ $\left[\mathrm{PF}_{6}\right]$ and SPG are used at $30^{\circ} \mathrm{C}$. The weight loss of ionic liquid supported in the membrane after the experiment was not observed. From these results, it was found that ionic liquids were stably kept in pores of a SPG support and benzene selectivity permeated the membranes as well as a polymeric membrane. As described in the previous papers [1-3], from the experimental data the overall mass transfer coefficients, $k$, and selectivity, $S$, were evaluated and shown in Fig. 2. From Fig. 2, permeation rates with SPG were lower than those of PVDF because of thicker membrane of SPG, suggesting that the controlling step of the permeation is the diffusion process through the membrane. Apparent diffusivities, $D$, through the membranes were calculated as

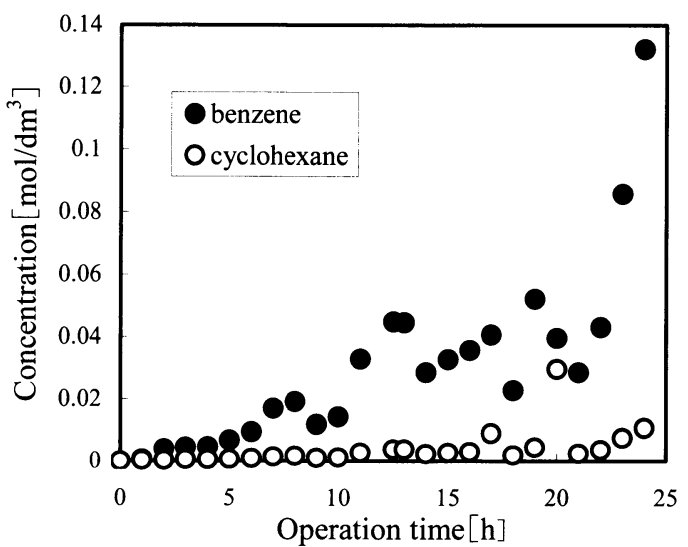

Fig.1 Time course of concentration in receiving phase. Ionic liquid; $\left[\mathrm{C}_{6} \mathrm{mim}\right]\left[\mathrm{PF}_{6}\right]$,Support;SPG

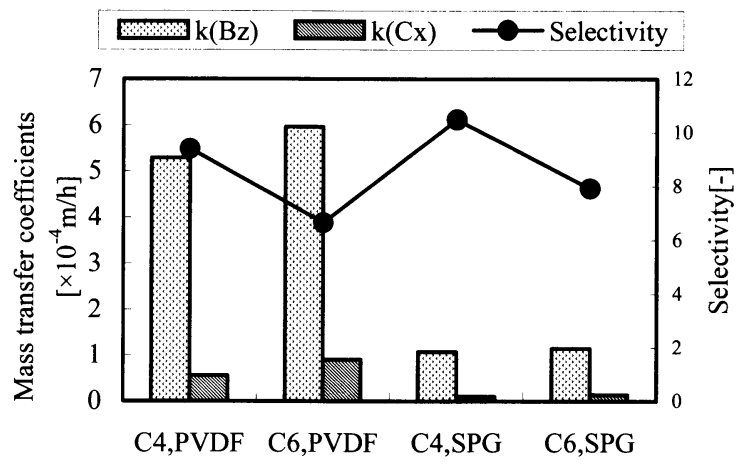

Fig.2 Effect of membranes on overall mass transfer coefficients and selectivity products of the overall mass transfer coefficients and membrane thickness, and listed in Table 1. Apparent diffusivities were controlled by the affinity of permeants and ionic liquids [1,2], suggesting that the permeation obeys the sorption-diffusion model. And effect of support on the permeation was found to be small. As a consequence, it is possible to use SPG membrane as a support of liquid membrane.

\section{Acknowledgment}

This work was supported by a Grant-in-Aid for Scientific Research (C) (No. 17560670) from the Japan Society for the Promotion of Science.

Table 1 Apparent diffusivities

\begin{tabular}{lcc}
\hline & $10^{10} D_{\mathrm{Bz}}\left[\mathrm{m}^{2} / \mathrm{h}\right]$ & $10^{10} D_{\mathrm{Cx}}\left[\mathrm{m}^{2} / \mathrm{h}\right]$ \\
\hline C4,PVDF & 792 & 84 \\
C6,PVDF & 894 & 135 \\
C4,SPG & 827 & 77 \\
C6,SPG & 881 & 107 \\
\hline
\end{tabular}

\section{References}

1) M. Matsumoto, K. Ueba, and K. Kondo, Solvent Extr. Res. Dev., Japan, 13, $51-59$ (2006).

2) M. Matsumoto, Y. Inomoto, and K. Kondo, J. Membr. Sci., 246, 77-81 (2005).

3) M. Matsumoto, M. Mikami, and K. Kondo, J. Jpn. Petrol. Inst., 49, 256 - 261 (2006).

4) M. Matsumoto, T. Ohtani, and K. Kondo, J. Membr. Sci., 289, 92-96 (2007).

5) N.M. Kocherginsky, Q. Yang, and L. Seelam, Separ. Purif. Technol., 53, 171 -177 (2007).

6) J. Yi and L.L. Tavlarides, AIChE J., 38, 1957 - 1968 (1992).

7) C.A. Cooper, Y.S. Lin, and M. Gonzalez, J. Membr. Sci., 229, 11 - 25 (2004).

8) G.T. Vladisavljević, M. Shimizu, and T. Nakashima, J. Membr. Sci., 250, 69 - 77 (2005). 